\title{
(1) pimmalina
}

\section{Brasil}
Autor(es):
Fonseca, Carmen
Publicado por: Imprensa da Universidade de Coimbra
URL persistente:
URI:http://hdl.handle.net/10316.2/38489
DOI:
DOl:http://dx.doi.org/10.14195/978-989-26-0995-9_4

Accessed : $\quad$ 26-Apr-2023 16:27:22

A navegação consulta e descarregamento dos títulos inseridos nas Bibliotecas Digitais UC Digitalis, UC Pombalina e UC Impactum, pressupõem a aceitação plena e sem reservas dos Termos e Condições de Uso destas Bibliotecas Digitais, disponíveis em https://digitalis.uc.pt/pt-pt/termos.

Conforme exposto nos referidos Termos e Condições de Uso, o descarregamento de títulos de acesso restrito requer uma licença válida de autorização devendo o utilizador aceder ao(s) documento(s) a partir de um endereço de IP da instituição detentora da supramencionada licença.

Ao utilizador é apenas permitido o descarregamento para uso pessoal, pelo que o emprego do(s) título(s) descarregado(s) para outro fim, designadamente comercial, carece de autorização do respetivo autor ou editor da obra.

Na medida em que todas as obras da UC Digitalis se encontram protegidas pelo Código do Direito de Autor e Direitos Conexos e demais legislação aplicável, toda a cópia, parcial ou total, deste documento, nos casos em que é legalmente admitida, deverá conter ou fazer-se acompanhar por este aviso.

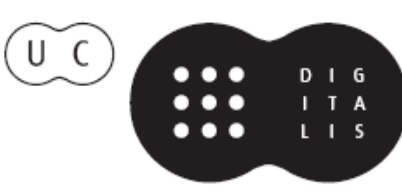




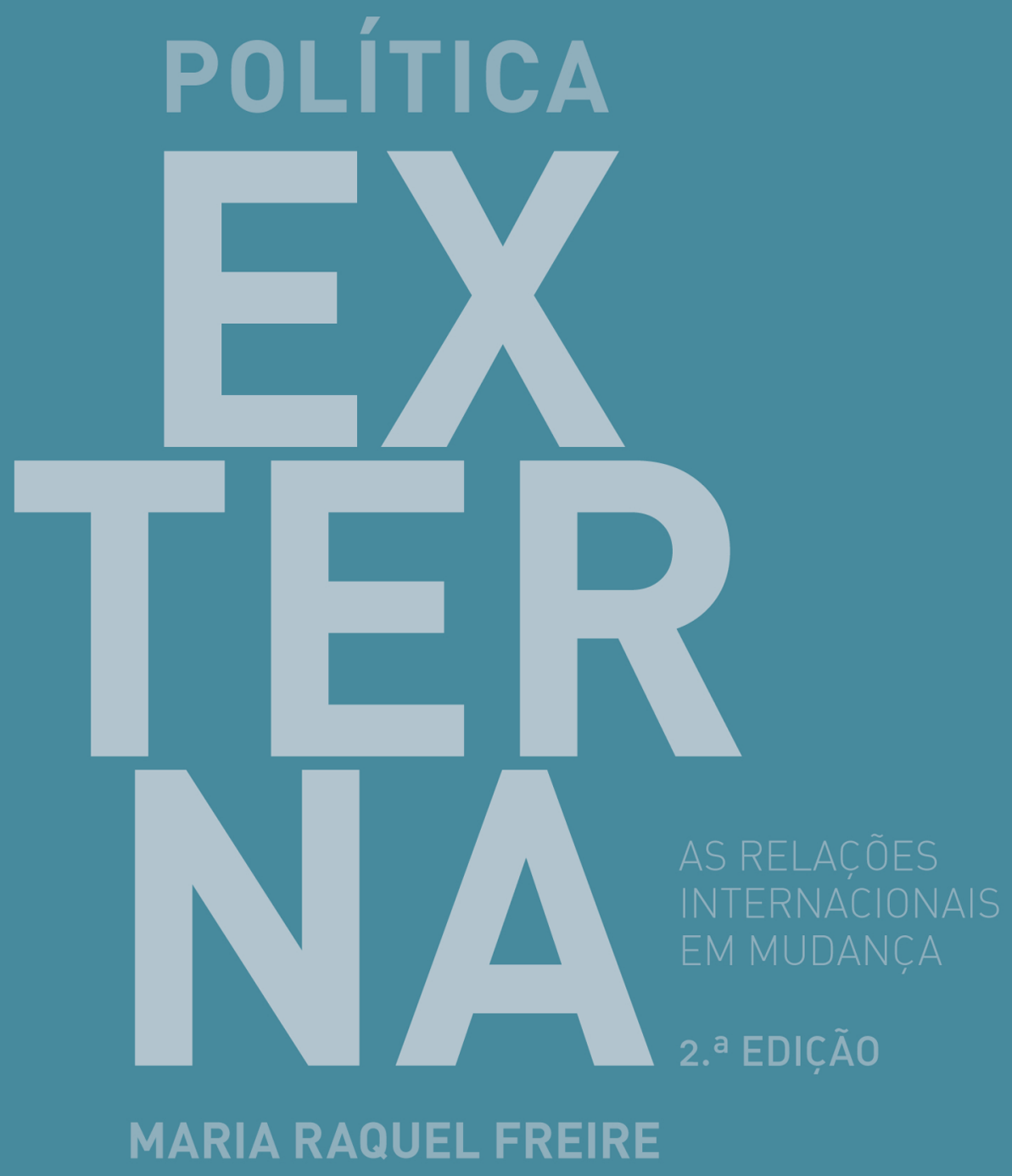

COORDENAÇÃO 


\section{CA P I T UL O 4}

\section{B R A S I L}

Carmen Fonseca

No Brasil, a transição para a democracia não marcou uma rutura nas principais linhas da política externa brasileira. Os princípios de política externa são constantes e transversais à grande parte dos diferentes momentos políticos, embora, por vezes, sejam instrumentalizados de forma diferente. O próprio regime militar caracteriza-se por uma maior oscilação de preferências, do que alguns períodos políticos (anteriores e posteriores) e a própria democracia. Gradualmente, muitas das estratégias adotadas, inclusivamente durante os anos do regime militar, foram recuperadas em momentos subsequentes. As principais alterações registam-se, como iremos ver de seguida, no que é definido como prioridade, e nas estratégias formuladas para a alcançar, que se ajustam em função das conjunturas internas e externas e, naturalmente, por influência dos próprios atores políticos.

\section{A formulação e decisão da política externa: \\ o Presidencialismo e autonomia do Itamaraty \\ O sistema político e partidário do Brasil é bastante comple- xo não obstante o seu enquadramento no perfil presidencialista.}


A Constituição de 1988 confere ao chefe do Executivo, o Presidente da República, amplos poderes sobre a administração pública ${ }^{18} \mathrm{O}$ que, por um lado define a forma como se relaciona com o Congresso e, por outro, como lida com as forças políticas dos vários estados federados. Deste modo, os estudos especializados têm distinguido o presidencialismo brasileiro dos restantes, definindo-o como "presidencialismo de coligação". Esta categorização justifica-se pelos múltiplos arranjos de coligações partidárias necessárias para a obtenção de maiorias no Congresso. Verifica-se por isso uma grande heterogeneidade ideológica e fragmentação parlamentar, que atingiu com Lula a maior diversificação, "Lula foi o presidente que mais partidos trouxe para o primeiro escalão do governo federal, 9 (...). Trata-se do mais fragmentado ministério formado na história do presidencialismo latino-americano" (Neto, 2007: 132).

$\mathrm{Na}$ verdade, as instituições políticas brasileiras concentram o poder no Executivo. O papel do Chefe do Executivo é reforçado constitucionalmente através da faculdade de editar medidas provisórias $^{19}$, o que lhe permite controlar e, consequentemente, enfraquecer o Poder Legislativo. No quadro dos sistemas presidencialistas, no caso brasileiro "é natural que o poder executivo seja o centro de gravidade do regime político" (Neto, 2007: 131), mas tal como acrescenta Octavio Amorim Neto, isso não é condição necessária do sistema presidencial (por exemplo, nos Estados Unidos o Congresso é o órgão mais relevante na condução dos assuntos internos). No Brasil, «a centralidade do Poder Executivo deriva não apenas da estrutura constitucional do país, mas também de fatores históricos

\footnotetext{
18 Pode nomear e demitir livremente os ministros de Estado.

19 As medidas provisórias são decretos que têm força de lei a partir do momento em que são publicados no Diário Oficial. Até 2001 o Congresso tinha 30 dias para votá-la, se nada fizesse, a medida expirava, o que acontecia na maioria dos casos. Em 1989 o Tribunal declarou que o Executivo poderia repetir o pedido, e assim fez. Em 2001, o prazo para apreciação pelo Congresso foi aumentado para 60 dias e as medidas só podem ser apresentadas uma vez (ver Neto, 2007).
} 
e do padrão de carreiras políticas" (Neto, 2007: 131), especialmente o tradicional papel do Estado na economia e no desenvolvimento do país que contribuiu para o fortalecimento do Executivo.

O que fica evidente é que, no sistema político brasileiro, o Poder Executivo tem o direito de iniciativa legislativa, e, consequentemente, influencia diretamente a agenda legislativa. Ao nível da política externa esta dinâmica é também uma prática comum. A intervenção do Congresso na formulação da política externa é muito reduzida, porque a competência que lhe é atribuída se cinge à ratificação de tratados e acordos internacionais ( Art $^{\circ} 49^{\circ}$ da Constituição do Brasil). Neste sentido, é comum o debate em torno da partilha do poder entre os órgãos Executivos e Legislativos, e o dilema sobre a delegação ou a abdicação das funções pelo órgão Legislativo. Embora à partida seja evidente a centralidade do Executivo, existem argumentos contraditórios. Maria Regina Soares de Lima e Fabiano Santos (1998) consideram que "[a]s posições do Presidente, como iniciador político, e as do Congresso, meramente de ratificação ex-post, geram um cenário em que é extremamente difícil para o legislador intermédio rejeitar as políticas negociadas pelo Executivo em fóruns internacionais" (Lima e Santos, 1998: 10) e, por isso, verifica-se uma demissão do Congresso das suas funções legisladoras em matéria de política externa.

Lima (2000) argumenta ainda que ao nível da política externa a delegação da autoridade de decidir é necessária quer seja para se obterem "políticas mais voltadas aos interesses da coletividade e não àqueles meramente eleitorais, seja em função do conhecimento especializado» (Lima, 2000: 282) exigido pela política externa «seja ainda para preservar as decisões em arenas internacionais» (Lima, 2000: 282). Por outro lado, Leany Lemos (2010) considera que não sendo a ratificação dos Tratados o único indicador da autoridade do Congresso, é insuficiente basear a argumentação apenas nesse elemento, sendo que a ausência do Congresso no processo de formulação e decisão da política externa não deve ser vista como 
uma abdicação, mas como uma delegação. Em contrapartida, o autor reforça que sistema brasileiro é tendencialmente pró-executivo, pois «as prerrogativas constitucionais favorecem o presidente e o poder executivo em qualquer assunto, mas especialmente naqueles relacionados com os assuntos externos" (Lemos, 2010: 4). No mesmo sentido, João Augusto de Castro Neves (2003) também argumenta que o "poder legislativo não é alheio ou desinteressado sobre questões internacionais" (Neves, 2003: 106) e que só delega as suas responsabilidades quando existe consenso sobre os assuntos em questão, ${ }^{20}$ como foi no caso do debate da criação do Mercosul. No estudo que desenvolveu o autor acrescenta que, no Brasil "a ausência de um mecanismo claro de delegação de autoridade é a principal causa da perceção de que o poder Legislativo está alheio às questões internacionais» (Neves, 2003: 117), contrariamente ao que acontece no sistema presidencialista norte-americano.

Assim, no quadro do poder Executivo, o processo de formulação e decisão da política externa no Brasil era tradicionalmente associado, exclusivamente ao Ministério das Relações Exteriores. O Itamaraty é tido como a instituição de onde, desde os tempos do Barão do Rio Branco, e com brechas efémeras, emanam as estratégias da política externa do Brasil. A centralidade do Itamaraty no processo de formulação da política externa resulta, em certa medida, da legitimidade que lhe fora atribuída, quer pelas elites políticas, quer pela sociedade, tendo em conta a especialização e o elevado grau de competência do corpo de diplomatas brasileiro. E, por outro lado, os detentores de cargos políticos, ou os que os almejam, não tendem a reconhecer qualquer impacto das medidas de política externa no

$20 \mathrm{O}$ autor analisa o caso das negociações do Mercosul referindo que o distanciamento do Parlamento das negociações foi devido ao consenso entre o Executivo e o Legislativo, já no caso da ALCA não existindo posições semelhantes «aumenta a vontade dos parlamentares de institucionalizar a participação nas negociações de política externa" (Neves, 2003: 107). 
plano interno logo, não centram o discurso nos temas de política externa, nem sequer suscitam o seu debate.

Todavia, quer devido ao processo de democratização do Brasil, quer devido às transformações do sistema internacional, aceleradas com o fim da Guerra Fria e a globalização, a partir da década de 1990, este processo começou a ser partilhado com outros atores e, especialmente, com o Presidente da República, através da diplomacia presidencial. Mas esta divisão de tarefas «não é de todo uma tradição brasileira" (Cason \& Power, 2009: 121), o Itamaraty sempre se caracterizou pela autonomia e isolamento burocrático na formulação da política externa, pelo elevado grau de profissionalização da diplomacia, bem como pelo monopólio das responsabilidades políticas (Cason \& Power, 2009: 119-120). A autonomia do Itamaraty reflete-se também na ausência de cunhos ideológicos e partidários no seio do corpo diplomático ${ }^{21}$, como refere Lima (2000) «a política externa é assunto de Estado, insulada da política partidária» (Lima, 2000: 290). Tal ideia começou, contudo, a ser questionada com mais veemência desde a filiação ao Partido dos Trabalhadores (PT) em 2009, do Ministro das Relações Exteriores, Celso Amorim. Nesse contexto, o ex-ministro das Relações Exteriores, Celso Lafer, referiu que o consenso da política externa brasileira como política de Estado foi algo que marcou a democracia brasileira, desde Sarney a Fernando Henrique Cardoso (FHC), mas que o fim desse consenso «é fruto da inédita partidarização da política externa promovida pelo governo de Lula" (Lafer, 2009). Como indicadores dessa partidarização Lafer destacou a nomeação de Marco Aurélio Garcia (membro histórico do PT) como Assessor diplomático do Presidente bem como a, já referida, filiação de Amorim ao PT. Mas note-se por exemplo que

21 Embora O PR possa nomear Embaixadores da sua confiança para assumirem os postos diplomáticos, em 2008 apenas se registavam dois casos de nomeações políticas: em Cuba e na Unesco, em todos os outros casos os Embaixadores foram nomeados a partir da estrutura diplomática (ver Mariano \& Mariano, 2008). 
em 2008 os únicos Embaixadores de nomeação política estavam em Cuba e na UNESCO, até mesmo nas organizações internacionais, como a OMC ou a UNCTAD, é comum encontrarem-se diplomatas de carreira, transversais aos vários governos.

Deste modo, o ponto de viragem, no que toca à redução da exclusividade da responsabilidade do processo de formulação e decisão da política externa, ocorre não só devido aos fatores atrás mencionados, mas também à figura de FHC, que assume a presidência da República em 1995. Até então, os anteriores Presidentes nunca tinham demonstrado interesse pela formulação da política externa (quer por opção pessoal, ou por fatores de política interna; como no caso de Itamar Franco que herdou três crise internas que exigiram que o Presidente se concentrasse na resolução dos problemas políticos, económicos e sociais internos e delegasse toda a matéria de política externa no Itamaraty). Pelo contrário, FHC (intelectual e académico), que já havia sido Ministro das Relações Exteriores de Itamar Franco, quando ocupa a Presidência, encarrega-se também da função diplomática para dar a conhecer ao mundo o Brasil democrático e restaurar a imagem do país. Inicia-se, assim, de forma empenhada, a chamada diplomacia presidencial, que o Presidente Lula da Silva continua de forma intensa. Este mecanismo demonstra que o processo de definição da política externa já não está apenas no Itamaraty, embora este continue a ser o ator central. É esta autonomia, formação e especialização que caracterizam o corpo diplomático que, de certo modo, ajudam a explicar a permanência dos princípios tradicionais na política externa brasileira.

Nacionalismo e Desenvolvimento, e a relação com os EUA

O Brasil foi o único país da América do Sul a enviar tropas para a $2{ }^{a}$ Guerra Mundial de apoio aos Aliados. Findo o conflito 
manteve-se um fiel parceiro dos Estados Unidos ${ }^{22}$ desempenhando um importante papel na criação da Organização dos Estados Americanos (em 1948) e na influência aos restantes países latino-americanos para a assinatura, em 1947, do Tratado Interamericano de Assistência Recíproca (TIAAR). Esperava-se que, tal como havia acontecido em 1918, os Estados Unidos reconhecessem o contributo brasileiro durante o conflito e incluíssem o país nas negociações internacionais de paz, contudo, tais expectativas saíram frustradas, ao que se somou a intensificação das relações dos Estados Unidos com a Argentina. Deste modo, nos anos imediatamente após o final da 2. ${ }^{a}$ Guerra Mundial registou-se uma indefinição da política externa do Brasil, especialmente nas relações com os Estados Unidos, que oscilavam entre uma dependência passiva (e frustrada), e o desejo de quebrar esse alinhamento.

A Presidência de Getúlio Vargas - tinha estado no poder como Chefe do Governo Provisório e depois como Presidente da República, entre 1930 e $1945^{23}$ - demonstra essa ambiguidade nas relações com os Estados Unidos, ou como o historiador Paulo Vizentini refere uma "política de ziguezagues", que teve consequências no isolamento do próprio Presidente. As políticas norte-americanas centravam-se na contenção da eventual expansão do comunismo, e que nem sempre iam de encontro aos interesses brasileiros. Consequência destas políticas e dos acordos militares ${ }^{24}$ celebrados entre os Estados Unidos e o Brasil foi a intensificação de um discurso antiamericano (que

22 Logo em 1949 o Presidente Gaspar Dutra visitou os Estados Unidos retribuindo a visita efetuada por Truman em 1947.

23 Após a Revolução de 1930, Getúlio Vargas foi nomeado Chefe do Governo Provisório, em 1933 foram realizadas eleições indiretas que o elegeram como Presidente da República, e em 1937 em vez das eleições previstas acabou por acontecer um golpe de estado que deu continuidade à permanência de Vargas no poder até 1945 .

${ }^{24}$ Em 1952 foi assinado o Tratado de Assistência Militar Brasil-EUA e, em 1953, o Acordo Militar Brasil-EUA que definia os termos para a venda de minerais aos EUA, sem quaisquer contrapartidas para o Brasil. 
visava diminuir a dependência em relação aos Estados Unidos) e a pressão sobre o Presidente que contribuiu para o enfraquecimento da sua base de apoio. A vontade de diminuir a dependência em relação aos Estados Unidos veio novamente à tona quando, em 1962, é promovida a Aliança para o Progresso, através da qual o Presidente Kennedy se comprometeu a ajudar economicamente a América Latina (com exceção de Cuba, que não subscreveu a adesão à Aliança).

O suicídio de Vargas, em 1954,põe na sua sucessão o vice-presidente Café Filho, e, com ele, um grupo mais adepto das políticas norte-americanas e menos adepto do projeto nacionalista. O desenvolvimento surgiu associado à segurança nacional, tendo sido criada a Escola Superior de Guerra, e promovida a ideia de que era necessário um alinhamento com o Ocidente, liderado pelos Estados Unidos. Na verdade, «o hiato representado pelo governo de Café Filho significou, em termos de política exterior, principalmente no que tange às relações com os Estados Unidos, um retorno ao período Dutra” (Cervo \& Bueno, 2008: 286). Deste modo, Vargas não conseguiu implementar o projeto nacional-desenvolvimentista que idealizara, mas continha as bases para a definição de uma nova política externa para o Brasil na década de 1960, com a Política Externa Independente.

Na segunda metade da década de 1950, o Presidente Juscelino Kubitschek implementou uma estratégia de desenvolvimento associada, num primeiro momento, a um bem sucedido plano económico (caracterizado pela industrialização e pela atração do capital estrangeiro), e, depois, pela retoma da «barganha nacionalista" de Vargas. Com base na ideia da interdependência entre os Estados, e da importância da cooperação internacional, promoveu, em 1958, a Operação Pan-Americana, com vista a criar uma estrutura regional para apoiar financeiramente os países latino-americanos, e que culminou com a criação do Banco Internacional de Desenvolvimento (BIRD). A sua criação recebeu algumas críticas 
devido à ausência de medidas concretas, mas acima de tudo, a Operação Pan-Americana significou a instrumentalização da política externa em prol do desenvolvimento nacional, pois «nunca na história brasileira do século XX valorizara-se tanto o contexto externo no equacionamento dos problemas nacionais" (Cervo \& Bueno, 2008: 288). No quadro do debate da descolonização, que marcava o contexto internacional da altura, o Brasil não adotou uma posição resoluta quanto à sua condenação, embora o seu discurso fosse nesse sentido 25 .

A primeira metade da década de 1960, com Jânio Quadros e João Goulart na Presidência, é marcada pela continuidade do projeto nacional-desenvolvimentista. De facto, apesar da instabilidade deste período tanto ao nível da Presidência como do Ministério das Relações Exteriores, tal não se refletiu na formulação da política externa. Entre 1960 e 1964, o Ministério das Relações Exteriores teve 5 Ministros, e a Presidência foi dividida entre o Presidente Jânio Quadros $^{26}$ e o seu vice-presidente, João Goulart, quando aquele renunciou ao cargo.

Ao nível da política externa destaca-se o papel do Ministro das Relações Exteriores, San Tiago Dantas (bem como Afonso Arinos e

25 Note-se por exemplo a aproximação intensa e positiva entre Kubitschek e Salazar. Dada a posição de colonizador de Portugal, Kubitshek tinha uma posição dúbia em relação ao colonialismo: por um lado, condenava tais ações e defendia a autodeterminação dos povos, mas por outro, não queria perturbar a relação com Portugal, e por isso não afirmava aquela posição com veemência.

${ }^{26}$ Jânio Quadros é caracterizado pela sua ousadia, que se refletiu na forma como abandonou a Presidência (logo em agosto de 1961) - ao julgar que recusariam o seu pedido de renúncia, enganou-se e o mesmo foi aceite. Impedia-se uma primeira tentativa de golpe de estado, já que a direita desde meados da década de 1950 desejava assumir o poder. Leonel Brizola consegue que o vice-presidente de Quadros, João Goulart, assuma a presidência e a solução consensual residiu na implementação de um sistema parlamentarista, em que Tancredo Neves foi nomeado Primeiro-ministro. Contudo, o governo formado era frágil e o populismo aumentava em desfavor do governo, antecipando o golpe de estado que teria lugar em 1964. 
Araújo de Castro ${ }^{27}$ ), que «dotou a Política Externa Independente de um corpo teórico consistente e colocou-a em prática, pois Quadros pouco ultrapassara o nível do discurso" (Vizentini, 2008: 26). Ao contrário de Kubitschek que concebia a política externa a partir de uma visão do hemisfério, a Política Externa Independente partia de uma conceção universal, assente no pragmatismo, na independência de ações, e no nacionalismo, traduzindo-se na multilateralização das relações internacionais do Brasil. Entendia-se também que a política externa promovia o desenvolvimento económico e era a base das reformas sociais, sendo, por vezes, entendida como típica de um país capitalista que reage à potência dominante (Vizentini, 2008). A Política Externa Independente visava a demarcação em relação aos Estados Unidos, ou a quaisquer outros países, não baseando as relações com os Estados em ideologias, e por isso «a busca de maior liberdade de movimentos no concerto internacional foi acompanhada de uma componente de frieza nas relações com os Estados Unidos» (Cervo \& Bueno, 2008: 311). A conceção de "Brasil potência», que se começava a desenhar, encaixava nesta estratégia já que o desenvolvimento e a industrialização seriam bem sucedidos «se o Brasil mantivesse certa autonomia diante dos Estados Unidos» (Vizentini, 2008: 31). Assim, paralelamente à relação pragmática com os Estados Unidos intensificaram-se as relações com a África e a Ásia, bem como com a Argentina, relacionamento entendido como uma forma de cooperação importante para os dois países aumentarem o seu grau de participação nos assuntos internacionais. No mesmo sentido, foram reatadas as relações diplomáticas com a URSS e, o Brasil não aprovou a expulsão ${ }^{28}$ de Cuba da OEA, em 1962. Todavia, relati-

27 Em 1963, nas Nações Unidas, o Ministro das Relações Exteriores, Araújo de Castro apresenta o discurso dos três ' $\mathrm{D}$ ': descolonização, desenvolvimento e desarmamento.

${ }^{28}$ A expulsão de Cuba da OEA foi aprovada com as abstenções da Argentina, Bolívia, Brasil, Chile, Equador e México. 
vamente à situação cubana, a crise dos mísseis de Cuba contrariou o argumento brasileiro, de que a situação era apenas um assunto interno, e deu mais credibilidade à posição norte-americana, do mesmo modo que, ao enfraquecer o governo, criou condições para o golpe militar que viria a acontecer.

Deste modo, as décadas de cinquenta e sessenta caracterizam-se pelas tentativas de demarcação em relação à dependência exclusiva dos Estados Unidos. Mas a influência norte-americana sentiu-se inclusivamente na queda do regime. O enfraquecimento interno do Governo de Goulart, e a falta de apoio dos Estados Unidos ao Governo, por um lado, e o apoio ao setor golpista, por outro, criaram as condições para o golpe militar em março de 1964. Esta ação foi antecedida pela renovação do Acordo Militar com os Estados Unidos, negociado pelo Itamaraty sem o conhecimento do Presidente; bem como pela operação Brother Sam no Atlântico, articulada pelos Estados Unidos e que, em caso de necessidade, previa a ajuda militar aos golpistas.

\section{O regime militar brasileiro e a Guerra Fria}

O período do regime militar, entre 1964 e 1985, foi marcado por algumas intermitências, ou um governo mais conservador ou um governo mais nacionalista, em que o epicentro esteve, mais uma vez, na definição da relação com os Estados Unidos e, consequentemente, na forma como o Brasil se afirmava no sistema internacional.

Ao analisarmos o regime militar como um todo verificamos que apenas o governo de Castelo Branco, (entre 1964 e 1967), tentou romper com a linha de política externa anterior ao golpe. Como previsto, começou por afirmar o projeto da Escola Superior de Guerra (com maior impacto a nível interno) instituindo a Constituição de 1967. A política externa previa o alinhamento com os Estados Unidos e o relacionamento entre os Estados com base nas ideologias. Nesse 
sentido, as relações com Cuba foram rompidas logo em 1964, assim como se enfraqueceram as relações comerciais com a URSS, a China e os continentes africano e asiático. Sob a alçada da OEA, o Brasil interveio no conflito da República Dominicana que, contrariamente ao esperado, contribuiu para denegrir a sua imagem na região 29. O regime brasileiro recebeu apoio económico dos Estados Unidos, do Fundo Monetário Internacional (FMI) e do Banco Mundial. Os parceiros norte-americanos apresentavam-se como a única alternativa face a uma conjuntura económica que tendia a agudizar-se, e o Ministro das Relações Exteriores afirmou inclusivamente que "o que é bom para os Estados Unidos é bom para o Brasil» (Vizentini, 2008: 41). Esta cumplicidade não se restringiu ao âmbito económico, também a nível diplomático se registou um regresso ao «âmbito hemisférico e bilateral» 30 das relações externas (Pecequillo, 2008). Mas, paralelamente, o Itamaraty conseguiu preservar um certo grau de autonomia em relação ao regime militar, e, gradualmente, foi reavivada a Política Externa Independente. É, certamente, neste quadro que se inclui o incremento das relações com os países africanos, pois a primeira missão comercial à África Ocidental teve lugar em 1965 lançando-se as bases da política africana do Brasil.

Em 1967, com a substituição de Castelo Branco por Costa e Silva, retomaram-se algumas ideias da Política Externa Independente, especialmente, no que se refere às questões económicas. Costa e Silva,

\footnotetext{
29 Na mesma lógica, o Brasil, sob influência dos Estados Unidos, tentou agregar parceiros para a criação de uma Força Interamericana de Defesa, mas tal não foi bem recebido.

30 O paradigma hemisférico-bilateral foi dominante entre 1902 e 1961 e defendia a preservação de uma boa relação com os Estados Unidos que oscilou entre um alinhamento pragmático ou automático. Após 1961 esta conceção é substituída pelo paradigma global e multilateral, que se resume à Política Externa Independente e que pressupõe a quebra do alinhamento automático com os Estados Unidos e a procura de novas parcerias e alianças (o melhor exemplo é o Pragmatismo Responsável de Geisel). Collor de Melo, Itamar Franco e FHC representam o paradigma hemisférico-bilateral em que se preconizam as relações com os países mais desenvolvidos e há o desejo de pertencer ao Primeiro Mundo (Pecequillo, 2008).
} 
da linha nacionalista do regime, inaugurou a chamada "Diplomacia da Prosperidade", associando o desenvolvimento à soberania e utilizando a diplomacia em prol do desenvolvimento económico. Contrariando rigorosamente as posições norte-americanas, foi quebrada a submissão inicial do Brasil aos Estados Unidos ${ }^{31}$ e foram definidas novas parcerias, especialmente entre os Países do Terceiro Mundo. Foi neste quadro que a política africana do Brasil também se redefiniu. No quadro regional foi assinado o Tratado da Bacia do Prata (Argentina, Bolívia, Brasil, Paraguai e Uruguai), com vista a promover a integração física daquela área.

No final da década de 1960, o discurso político era marcado pela conceção de "Brasil a potência» e pela "Diplomacia do interesse nacional». O Brasil não era autopercecionado como um país do Terceiro Mundo, nem se preconizavam essas alianças, recuperava-se novamente a ideia da necessidade de uma relação cordial com os Estados Unidos. Ainda assim, em 1972, o Ministro das Relações Exteriores, Gibson Barboza, realizou uma missão a vários países africanos contribuindo para o fomento da política africana ${ }^{32}$. Simultaneamente, Médici permitiu conjugar as boas relações com os Estados Unidos com o seu projeto de desenvolvimento nacional, o que foi facilitado também pela posição norte-americana em ter um aliado estável na região (quando os governos de esquerda e as guerras civis tendiam a proliferar).

$\mathrm{O}$ interesse nacional foi ainda favorecido pelo «milagre económico» que o Brasil conheceu entre 1970 e 1973, e que contribuiu para o aparecimento de uma classe média consumidora. Todavia,

31 Tal posição deve-se, em certa medida, a um desentendimento do Presidente brasileiro com o subsecretário de Estado norte-americano para a América Latina.

32 Alguns autores (Lechini, 2008) entendem que foi esta viagem, em 1972, que definiu a aproximação do Brasil a África, enquanto outros (Saraiva, 1996) entendem que tal só foi possível devido ao que começara a ser delineado na década de 1960 , com a missão comercial em 1965. Todavia, nessa altura o contexto ainda não era favorável à cooperação com o continente africano, pois a falta de apoio explícito às colónias africanas nem sempre jogou a favor do Brasil. 
este período foi perturbado pelo choque petrolífero de 1973 que ditou, não só, a quebra da prosperidade, mas também o fracasso da aproximação aos países árabes, e com isso a falência do projeto de desenvolvimento do Brasil. Assim, quando Ernesto Geisel chegou ao poder, em 1974, começou por implementar o II Plano Nacional de Desenvolvimento que previa a diversificação das fontes de energia, a capacitação tecnológica e a definição do Estado como o maior agente produtivo, com o objetivo de controlar o elevado deficit comercial e contribuir para a estabilidade do país.

O início do processo de abertura política do regime registou um sinal importante com o Presidente Geisel que desde a sua tomada de posse definiu a abertura como a sua prioridade, começando por pôr fim à censura da imprensa (ver Spektor, 2004: 210-214). A própria política externa foi utilizada para reunir consenso interno e como moeda de troca com as fações militares rivais do regime. Mais concretamente, no que se refere à política externa, o Ministro das Relações Exteriores de Geisel, Azeredo da Silveira apresentou-se como um ator-chave, definindo juntamente com o Presidente, e com base na Política Externa Independente da década de 1960, o Pragmatismo Responsável. Esta conceção visava conciliar as necessidades económicas com as estratégias de política externa, direcionando-se para os países árabes e com outras potências regionais asiáticas e africanas. Deste modo, recuperou-se a noção de autonomia da política externa, especialmente em relação às grandes potências, "Os anos Geisel situam-se confortavelmente na tendência geral a maior e mais veloz asserção da autonomia nacional face aos estritos limites impostos pelo sistema internacional da Guerra Fria" (Spektor, 2004: 196). Devido às transformações ocorridas no sistema internacional, e sob a retórica do início da década de "Brasil a Potência", Azeredo da Silveira pretendia projetar o Brasil na cena internacional, acreditando que os países em desenvolvimento poderiam ganhar espaço e influenciar a agenda internacional. Nesse sentido, foi definida cla- 
ramente a posição do Brasil em relação ao colonialismo. E, apesar da amizade com Portugal, a diplomacia brasileira foi a primeira a reconhecer a independência de Angola, em 1975.

No que concerne às relações com os Estados Unidos, destaca-se a cessação do Acordo Militar 33 entre os dois países em 1952, dadas as pressões norte-americanas para que o Brasil não celebrasse o Acordo Nuclear com a Alemanha. No entender de Spektor (2009) a tese da "rivalidade emergente» - que defende que o processo de modernização e industrialização do Brasil contribuiu para o aumento da rivalidade com os Estados Unidos - não é suficiente para explicar o fracasso do relacionamento entre o Brasil e os Estados Unidos, na década de 1970, é necessário atentar também no empenho tanto de Azeredo da Silveira como de Richard Nixon. Mas, mesmo assim, apesar das suas tentativas "os planos de convergência conviveram com dúvidas profundas e recorrentes desconfianças de ambos os lados» (Spektor, 2009: 185). No mesmo sentido, Cervo \& Bueno (2008: 442) referem que "as relações entre os dois países permaneceram nos anos 1980, como nos anos 1970, à espera de propostas substantivas e igualitárias, desprovidas de egoísmos nacionais, para se alcançarem ao nível das necessidades e conveniências bilaterais».

O processo de abertura político iniciado com Geisel ${ }^{34}$ foi continuado pelo Presidente João Figueiredo, apelidado como o «Presidente da abertura", que implementou, logo em 1979, uma reforma partidária. O seu mandato foi influenciado, quer, pelo segundo choque petrolífero de 1979 (em termos económicos), quer pelo fim da détente. Por um lado, o choque petrolífero contribuiu para a deterioração

33 Note-se que o Brasil e os Estados Unidos voltaram a assinar um novo Acordo Militar apenas em abril de 2010.

34 Geisel mostrou-se contrário a algumas das ações levadas a cabo, a partir de 1976, pelos órgãos de repressão, e que incluíam atentados, sequestros e assassinatos. O Presidente demitiu o Comandante do Exército, o Ministro do Exército e o Chefe de Gabinete Militar. 
da situação económica mundial que atingiu o Brasil (e a América Latina) através da "crise da dívida". Por outro lado, o fim da détente, e a agudização das relações entre o bloco americano e o bloco soviético contribuíram para que, em 1981, o Presidente Ronald Reagan instituísse uma alta taxa de juro aumentando a dívida externa de países em desenvolvimento, como o Brasil. Mas a par das dificuldades económicas, o Brasil continuava a tentar demarcar-se das propostas norte-americanas - recusando, por exemplo, as propostas de militarização do Atlântico Sul, mas, em contrapartida, consolidando as relações com alguns Estados africanos, nomeadamente a Nigéria e outros Estados no Golfo da Guiné. A diversificação das relações visava não só suprir as necessidades energéticas do Brasil, assim como unir os países do "sul» de modo a pronunciarem-se a uma só voz nas organizações económicas multilaterais.

\section{A transição democrática: mudança de regime sem mudança de política}

No seguimento das reformas introduzidas por Geisel e Figueiredo criaram-se as condições mínimas necessárias para que, em 1984, sob o lema das "Diretas já», se realizassem eleições. Das eleições de 1984 saiu vencedor Tancredo Neves que acabou por não tomar posse dadas as suas condições de saúde. O seu lugar foi ocupado por José Sarney, eleito vice-presidente. Assim, a democracia reinstalou-se no Brasil de forma gradual não se verificando qualquer processo revolucionário e, por isso, também, ao nível da política externa não se verificou qualquer corte abrupto com o passado. Mas a linha de continuidade deriva também da componente institucional e burocrática encontrada no Itamaraty, o que "garante continuidade nas escolhas e relativa consistência nas orientações de política” (Lima, 2000: 289). Ao mesmo tempo que se reconhecia que o novo Governo 
deveria procurar um consenso mínimo com os atores sociais de modo a evitar qualquer rutura institucional, o que culminou com a adoção da Constituição em 1988.

José Sarney chegou ao poder com um contexto interno que não era de todo favorável. À explosão simultânea de três crises, política, económica e social, somava-se a complexidade do país, que o próprio Presidente definiu como "um Brasil composto por diversos Brasis" (Sarney, 1986). As primeiras medidas do Governo prenderam-se com a estabilização do país, a convocação da Assembleia Constituinte, a promoção do crescimento económico e o investimento no bem-estar social. A recuperação económica exigiu também que a nível externo se adotasse uma política firme para reduzir a dívida externa, resultado do esgotamento do modelo económico iniciado na década de 1930 (quando o Estado era o ator central). De modo a estabilizar a economia através da redução dos valores da inflação, Sarney implementou em 1986, com êxito, o Plano Cruzado.

A conjuntura económica também se repercutiu na atuação externa. No seguimento da "crise da dívida", adotou-se uma moratória aos Estados Unidos. O discurso do Presidente era bastante crítico da atitude norte-americana, que no seu entender, tratava o Brasil, um país rico e com um grande potencial, como um "país de segunda". A incompatibilidade de posições entre o Brasil e os Estados Unidos foi evidente, quer nas questões da organização do comércio continental e internacional, quer nas tentativas de integração da região. O segundo Ministro das Relações Exteriores de Sarney, Abreu Sodré (antecedido por Olavo Setúbal), além de reatar relações com Cuba, reconheceu a necessidade de diversificar as parcerias não se alinhando, exclusivamente, aos Estados Unidos. Por conseguinte, este período é marcado por um fortalecimento da cooperação entre o Brasil e a Argentina ${ }^{35}$ (assim como com o Uruguai). Os dois países

35 O Brasil e a Argentina assinaram a Ata para a Integração e Cooperação Económica, em 1981, e o Tratado de Integração, Cooperação e Desenvolvimento 
associaram-se ainda ao Grupo de Apoio a Contadora, como forma de manifestarem o seu desagrado pelas políticas norte-americanas para a América Latina. Em retaliação, os Estados Unidos aplicaram sanções comerciais ao Brasil, o que comprova o desacordo norte-americano quanto às tentativas de integração entre as duas principais potências da América do Sul. Por conseguinte, o Brasil procurou novos parceiros noutras áreas regionais, como a República Popular da China e a URSS, ao mesmo tempo que desenvolveu e aprofundou as suas relações com os países africanos e do Médio Oriente.

O governo de José Sarney foi, essencialmente, um período de transição, em que as dificuldades económicas do país e as condições políticas e sociais internas, bem como as incompatibilidades com os Estados Unidos, ainda num contexto de Guerra Fria, ditaram muitas das opções que se fizeram.

Os dois governos seguintes, de Collor de Mello e de Itamar Franco, encaixam-se ainda num período de indefinição e ajustes. Na verdade, as transformações na política internacional, com o fim da Guerra Fria, tiveram consequências também para o Brasil, nomeadamente com a importância crescente das dinâmicas de regionalização, que criavam novas condições para a consolidação de grandes potências regionais, bem como para a autonomia da América do Sul, e forçaram o início de uma revisão das prioridades da política externa brasileira. No Brasil, gerou-se um grande debate entre os que defendiam a revitalização da relação com os Estados Unidos, reformando a política interna de acordo com as suas orientações, e os que defendiam uma correção da postura global do país, de modo a adaptar-se às mudanças internacionais. Collor de Mello, eleito em 1989, optou pela primeira conceção, pois, no seu entender, "a proposta de modernização econômica pela privatização e abertura é a esperança de completar a liberdade política, reconquistada com

Brasil-Argentina, em 1988. 
a transição democrática" (Mello, 1990). Collor de Mello optou pelo alinhamento com os Estados Unidos e adotou as medidas neoliberais propostas pelo "Consenso de Washington", e "a chegada de Collor de Mello à presidência trouxe à arena do processo decisório de política externa uma corrente liberal, minoritária no Itamaraty, mas seu impeachment reduziu suas influências até os dias atuais»36 (Saraiva, 2010: 2). Contrariamente ao Governo anterior, a política externa teve como ponto de atração a relação com os Estados Unidos, entendida por alguns autores como a «ilusão norte-americana de Collor» (Vizentini, 2003: 61) Se o jovem Presidente começou por defender a inevitabilidade da aproximação aos Estados Unidos para modernizar o país, cedo reconheceu as desvantagens desse alinhamento. O insucesso das políticas económicas e a deterioração da situação política, levaram-no a chamar para o Itamaraty o Embaixador Celso Lafer que introduziu novos padrões de referência para o Brasil, diminuindo a excessiva centralidade dos Estados Unidos. Lafer entendia que a "a autoridade do Itamaraty" (Vigevani \& Cepaluni, 2009: 42) era necessária para uma política externa efetiva, e os seus discursos destacavam a "adaptação criativa» da política externa e a «visão de futuro».

No plano regional, destaca-se a articulação entre o Brasil e a Argentina que culminou com a criação do Mercosu, em 1991, entendido acima de tudo como um mecanismo para acelerar a liberalização da economia do Brasil, uma das prioridades de Collor de Mello (a importância estratégica da estrutura regional só viria a ser reconhecida com Itamar Franco).

36 No Itamaraty têm existido duas correntes de pensamento da política externa, que Miriam Gomes Saraiva (2010) define como os "autonomistas" («desenvolvimentismo" económico, autonomia, universalismo, inserção internacional, reforma da ordem internacional) e os «institucionalistas-pragmáticos" (liberalização económica, apoio crítico aos regimes internacionais, defesa da autonomia e soberania, prioridade da região sul-americana). Vide, entre outros, Saraiva 2010. 
Itamar Franco assumiu a presidência num contexto de crise - não muito diferente daquele deixado por Sarney, no final do seu mandato. Deparando-se com a necessidade de responder à crise económica interna, o Presidente Itamar concentra todos os seus esforços nesse campo, transferindo as tarefas de política externa, na sua totalidade, para o Itamaraty, que tinha como Ministro das Relações Exteriores, Fernando Henrique Cardoso.

O curto mandato de Itamar Franco foi, em parte, distinto do anterior: em vez de fragilizar a condição do país conseguiu definir algumas estratégias para a política externa e económica, que nem sempre seguiram as diretrizes dos Estados Unidos. Embora a perceção internacional inicial fosse de que o país iria adotar uma atuação mais nacionalista para se diferenciar de Collor, tal não aconteceu, «O que se percebeu foi a manutenção das políticas iniciadas anteriormente, paralelamente à adoção de um posicionamento marcado pela condição de país em desenvolvimento" (Hirst \& Pinheiro, 1995: 11). Tanto no quadro da política externa como da recuperação económica, FHC teve um papel fulcral. Ao nível da política externa começou por reorganizar o Itamaraty, e reconheceu a necessidade de "adicionar uma base sólida à nossa própria região, se não for por outra razão, pelo menos para aumentar a nossa capacidade de negociação. (...)» (Fernando Henrique Cardoso apud Vigevani \& Cepaluni, 2009: 47), embora isso não significasse uma rutura das relações com os Estados Unidos. O desenvolvimento do Mercosul é aprofundado através da assinatura, em 1994, do Protocolo do Ouro Preto que institucionalizou a sua estrutura intergovernamental e implementou o consenso como processo de tomada de decisão. O Mercosul era, então, entendido como fundamental para o comércio da região, mas também como forma de compensar a dependência em relação aos Estados Unidos.

Em 1992, a substituição de FHC por Celso Amorim não significou uma mudança no rumo da política externa. Contudo, à estratégia 
de valorização da região somou-se a definição de uma estratégia de inserção internacional para afirmar a posição do país, que fora abalada com Collor. No entender de Amorim, tal inserção internacional poderia ser feita através da reforma do Conselho de Segurança das Nações Unidas ${ }^{37}$, ambição que o Brasil tem há vários anos. Começavam então a ser delineadas e implementadas algumas estratégias de ação externa, ao mesmo tempo que o lançamento do Plano Real aliviou a crise económica do país.

O Plano Real, implementado em 1994 pelo Ministro da Fazenda, Fernando Henrique Cardoso, permitiu controlar a inflação, contribuindo para o aumento do consumo ${ }^{38}$ e a recuperação da economia brasileira, e serviu para melhorar a posição do Brasil no contexto internacional. Noutro domínio criou, ainda, as condições para a vitória de FHC nas eleições presidenciais de 1994.

Fruto das transformações do sistema internacional, no início da década de 1990, Collor de Melo "pôs em xeque os princípios da política externa adotada até então, mas que não foi capaz de consolidar um novo conjunto de princípios» (Saraiva, 2007: 45), embora a tentativa de modernização seja recuperada posteriormente. Deste modo, o período intercalar (após o fim do regime militar e a consolidação da democracia) é uma "crise de transição", ou uma "dança de paradigmas» (Cervo \& Bueno, 2008: 455), em que todas as novas orientações se começam a esboçar - o Mercosul, a reforma monetária, a diversificação de relações, a candidatura ao Conselho de Segurança - sem se forjar contudo um (novo) modelo e persistindo um balouçar entre os «autonomistas» e os «liberais».

37 Neste período, o Brasil foi eleito por dois anos membro do Conselho de Segurança das Nações Unidas, participou em sete operações de paz, apresentou a proposta de uma agenda de desenvolvimento, e incrementou o relacionamento com os países vizinhos.

38 A euforia provada pelo consumo, e que contribui para os anos de ouro da economia, ocultava os deficits do comércio externo e da balança de pagamentos, que só se revelariam no segundo mandato do Presidente Fernando Henrique Cardoso. 


\section{A revelação internacional do Brasil}

Fernando Henrique Cardoso, em 1995, introduziu uma nova atitude nas estratégias da política externa do Brasil preconizando uma intervenção mais ativa do Brasil na política internacional, demonstrada através da vontade de «influenciar o desenho da nova ordem» internacional (Oliveira, 2010: 14). O discurso do novo Ministro das Relações Exteriores, Luiz Felipe Lampreia expressava também essa ideia, "nem a maior autonomia, nem o aumento da nossa capacidade de influência poderão ser alcançados por meio do isolamento ou da pretensa autosuficiência” (Lampreia, 1998: 9).

Por um lado, a administração de FHC demonstrou-se empenhada na política externa e na área económica, e por outro, habilmente separou estes dois domínios, reformando as atribuições do Itamaraty e as do Ministério da Fazenda, e concentrando uma parte importante da política externa nas mãos do Presidente da República. No que se refere à política externa, os dois mandatos de FHC foram marcados pela "diplomacia presidencial»; pela aposta na região Sul-americana através da integração regional e da revalorização do Mercosul; pela adoção das regras e dos regimes internacionais, e num segundo momento, pela intensificação das relações com o Sul. A «diplomacia presidencial» valorizou a inserção internacional do país, através das visitas oficiais realizadas pelo Presidente, mas não diminuiu a importância da afirmação regional do Brasil. FHC quis conciliar uma dimensão global com uma outra mais centrada na América do Sul, espelhada na postura de participação e de integração do Brasil - integração não só em termos regionais, como também integração do Brasil no que se refere às normas e aos regimes internacionais. Como referiu Lampreia, «a política externa do Presidente FHC busca a autonomia pela integração, ou seja, ao invés de uma autonomia isolacionista, uma autonomia articulada com o meio internacional» (Lampreia, 1998:11). Nesse sentido, foi possível registar também uma coincidên- 
cia entre a definição da identidade do Brasil e os valores universais, ao que Luiz Felipe Lampreia denominou de "convergência crítica".

As relações Sul-Sul começaram a ser desenhadas no final do governo de FHC, motivadas pela conjuntura internacional que se traduziu no ceticismo de FHC quanto à associação automática com as normas do neoliberalismo, que se mostraram negativas nos países em desenvolvimento (como o Brasil, ou a Argentina). Na verdade, FHC começou por recuperar, no início do seu mandato, o modelo neoliberal, que fracassou com Collor de Mello, embora reclamasse simultânea e paradoxalmente, a reforma do sistema internacional. Mas a verdade é que, no final do segundo mandato, FHC reconheceu as fragilidades do modelo neoliberal: a conjuntura internacional, associada à crise financeira e cambial de 1999 desmoronou o projeto brasileiro, pois «todo o cenário mundial em que o governo baseara a sua inserção internacional veio abaixo" (Vizentini, 2008: 98). Em 2001, a Argentina passou por uma grave crise económica que anunciou o colapso do neoliberalismo e das políticas recomendadas pelo FMI e pelo Banco Mundial no país e na região. Por conseguinte, no discurso que, em 2001, FHC fez na abertura da Assembleia Geral das Nações Unidas refere que "nosso lema há de ser o da 'globalização solidária', em contraposição à atual globalização assimétrica” (Folha Online, 2001).

$\mathrm{Na}$ verdade, o relacionamento com o Norte (símbolo dos países ricos) foi uma prioridade da política externa de FHC, que se aproximou não só dos Estados Unidos, mas também da Europa e do Japão, colocando em segundo plano as relações com os países menos desenvolvidos, e os países africanos em particular. Aliás, a aproximação do Brasil a África durante os mandatos de Cardoso é normalmente apelidada de "opções seletivas" por existir uma grande precisão nas parcerias estabelecidas.

Nesse sentido, a relação com os Estados Unidos manteve-se estável. As incompatibilidades registaram-se no respeitante às políticas 
comerciais e aos objetivos de integração, especialmente à proposta norte-americana para a criação de uma Área de Livre Comércio das Américas (ALCA). Em todo o caso, verificou-se, também, uma aparente alteração da postura brasileira, pelo menos em termos retóricos, quanto ao projeto da ALCA, mas que, na prática, não surtiu grandes efeitos. A inconsistência da posição brasileira visava apenas evitar qualquer possibilidade de isolamento do Brasil, caso o projeto de criação da ALCA se viesse a concretizar. O final do mandato de Cardoso registou, contudo, um enfraquecimento do relacionamento com os Estados Unidos, que se deveu, sobretudo, à alteração da estratégia internacional dos Estados Unidos, esboçada após os ataques do 11 de setembro, que passou a privilegiar as questões de segurança e a dar menos importância ao sul do continente. Ora, o fortalecimento da postura unilateral norte-americana, levou FHC a incrementar a vertente multilateral, diversificando as relações e aproximando-se das potências regionais ${ }^{39}$.

Concomitantemente, a realização da Cimeira da América do Sul, em Brasília em 2000, representou um marco importante na política externa brasileira ao propor a Iniciativa para a Integração da Infraestrutura Regional Sul-Americana ${ }^{40}$ (IIRSA) e dando ao discurso diplomático brasileiro um caráter autonomista, que de certo modo, chocava com o projeto da ALCA. A realização da Cimeira simbolizou a redefinição da identidade regional do Brasil, que, gradualmente, deixou de se referir à América Latina, considerada uma construção artificial e imprecisa, para utilizar o conceito de América do Sul,

39 Momento que coincide também com a apresentação, pela Goldman Sachs do acrónimo BRIC, destacando o potencial de crescimento das economias destes países (Brasil, Rússia, Índia e China).

40 A IIRSA corresponde a uma iniciativa dos 12 países sul-americanos, tendo sido institucionalizada em 2000, na Cimeira dos Presidentes da América do Sul. Pressupõe a realização de ações conjuntas para promover o processo de integração política, económica e social da América do Sul, estimular a integração e o desenvolvimento de sub-regiões isoladas. Ver [http://www.mp.gov.br/secretaria . asp?cat=156\&sub=302\&sec $=10$ ] (consultado a 15 de março de 2010). 
uma construção política onde mais facilmente o Brasil pode fazer valer os seus interesses. A definição da área regional da América do Sul era algo que já vinha sendo conceptualizado desde os tempos do Barão do Rio Branco, mas foi com Fernando Henrique Cardoso que se consolidou, consequência dos processos de regionalização e globalização que ocorreram, e à tomada de consciência de que "a América do Sul constitui uma unidade física contígua, que favorece as oportunidades de cooperação económica” (Lafer, 2002: 67).

Verificamos, portanto, que os anos de FHC permitiram consolidar a democracia brasileira e projetar a imagem do Brasil no exterior - democrático, adepto das normas e valores universais, com uma conduta pacífica - embora alguns autores considerem que não se tenha incrementado, simultaneamente, um desenvolvimento sólido (Vigevani \& Oliveira \& Cintra, 2003: 58). A passagem de FHC para Lula da Silva, em 2003, permitiu que se continuassem as políticas económicas iniciadas, contribuindo para o crescimento e estabilidade económica do país, e simultaneamente, para o aumento do protagonismo internacional do Brasil.

Ao nível dos princípios históricos ${ }^{41}$ da política externa brasileira, o Governo de Lula pode ser visto como um contínuo dos anos de FHC, pese embora os ajustes efetuados, pois "ao exercerem juntos dezasseis anos de mandato, são determinantes para a evolução do modelo brasileiro de inserção internacional na passagem do século XX para o XXI» (Cervo \& Bueno, 2008: 491). Em 2003, o discurso de tomada de posse do Presidente Lula da Silva acentuava a ideia de mudança porém, tal não se concretizou, pelo menos nos eixos que definem a política externa brasileira. Muitas das parcerias consolidadas por Lula tiveram a sua génese ainda durante a administração de Cardoso, «mas Lula deu uma nova ênfase a este aspeto da agenda

41 Como por exemplo o pacifismo, a não-intervenção, a autodeterminação e a segurança coletiva. 
internacional do Brasil" (Vigevani \& Cepaluni, 2009: 81), ou como afirmou o Ministro das Relações Exteriores, Celso Amorim,

os princípios básicos são os mesmos. Mudaram as ênfases e as intensidades com que certos temas são tratados. Quando eu era embaixador na ONU, o Brasil sempre teve proximidade com os africanos. Não se pode dizer, portanto, que a boa relação com a África é uma invenção do governo atual. Agora, vá comparar a intensidade dessa relação antes e depois. (Amorim, 2008)

A política externa desenvolvida nos dois mandatos de Lula reflete não só os constrangimentos e oportunidades do ambiente internacional e interno, como o aproveitamento das oportunidades criadas pelo anterior Governo. Os temas e relacionamentos privilegiados são, na sua maioria, reavivados, e não uma novidade. É possível registar também a recuperação da instrumentalização da política externa em prol do desenvolvimento nacional, «no meu Governo, a ação diplomática do Brasil estará orientada por uma perspetiva humanista e será, antes de tudo, um instrumento do desenvolvimento nacional» (Silva, 2003).

Lula da Silva define o multilateralismo como um instrumento prioritário da sua estratégia externa, bem como as relações Sul-Sul. A demarcação da dependência exclusiva das grandes potências é concretizada através da participação em organizações internacionais, da definição de uma agenda externa própria e da prioridade dada à diversificação de parcerias. Tal é representado, por exemplo na posição firme (e por vezes intransigente) do Brasil nas negociações da Organização Mundial do Comércio, que em 2003 reúne um conjunto de países em desenvolvimento e com posições comuns em torno do que ficou conhecido com o Grupo dos $20^{42}$, funcionando como um

42 O Brasil faz parte também do G20 que é um fórum de diálogo e cooperação das maiores economias, criado em 1999 como resposta às crises económicas dos anos 1990. O Brasil acolheu a cimeira do G20 em 2008. 
mecanismo para contrabalançar o poder de influência dos países ricos relativamente às questões agrícolas e comerciais. A estratégia foi expressa também no discurso de tomada de posse do Presidente afirmando que "a democratização das relações internacionais sem hegemonias de qualquer espécie é tão importante para o futuro da humanidade quanto a consolidação e o desenvolvimento da democracia no interior de cada Estado" (Silva, 2003).

É, neste sentido, que se assinala a "autonomia pela diversificação" (Viegavi \& Cepaluni, 2009) na política externa de Lula, estratégia que pela variedade de parcerias visa aumentar a capacidade de influência do Brasil na região e no mundo. Durante o mandato de FHC, essa dinâmica foi desenvolvida de forma mais moderada. As jogadas brasileiras em arenas diplomáticas, ora complementares ora alternativas, visam, justamente, a diversificação de parcerias e a emancipação face aos atores dominantes do sistema internacional. Note-se, por exemplo, a recuperação da política africana, desenvolvida por Lula, aproveitando os espaços deixados em aberto pelas grandes potências. Todavia, não foi descurado o relacionamento com o Norte, tanto com os Estados Unidos como com a União Europeia (UE). A parceria estratégica institucionalizada com a UE, em 2007, é disso exemplo, simbolizando o reconhecimento europeu do papel regional e internacional do Brasil. Gradualmente, Lula da Silva contribuiu para a definição de uma postura assertiva do Brasil, que muito se parece com o Pragmatismo Responsável de Geisel, da década de 1970, não interessando os vínculos ideológicos para o relacionamento entre os países. E, por isso mesmo, algumas estratégias são marcadas por uma certa inconstância que deriva dos interesses temporais do Brasil.

No que toca à região, em 2003, o Ministro das Relações Exteriores afirmava que "a América do Sul será nossa prioridade" (Amorim, 2003). Registou-se a proliferação de mecanismos de integração e diálogo, como a UNASUL e o Conselho sul-americano de Defesa, a 
par do diálogo com a Venezuela ou a Bolívia, e a missão no Haiti. O Mercosul é percecionado como um instrumento político que agiliza negociações internacionais a diversos níveis (inclusivamente, como alternativa à ALCA), conduzindo a vantagens económicas e comerciais. As relações comerciais do Brasil, no quadro do Mercosul, são bastante significativas, e especialmente as trocas com a Argentina conheceram um aumento durante o mandato de Lula.

Mas, como evidenciámos, as relações extrarregionais juntaram-se a esta opção, devido às vantagens que apresentavam para a afirmação internacional do Brasil e para a multipolaridade das relações internacionais, defendida por Lula. Na verdade, o Brasil rentabilizou os vários tabuleiros de atuação internacional, através da participação nos fora multilaterais (quer seja nas organizações internacionais, como a Organização Mundial do Comércio, quer seja no fomento de fóruns multilaterais de diálogo, como o IBSA, as cimeiras BRIC, ou o G20), do incremento do diálogo bilateral com diversos países (note-se por exemplo as relações com alguns países da União Europeia, como a França ou a Alemanha, e Portugal), assim como aumentando a sua expressão diplomática no continente africano e asiático.

E daqui deriva um dos debates atuais sobre a política externa do Brasil: liderança regional ou liderança internacional? Na verdade, para o Brasil permanece a dificuldade em encontrar consenso junto dos vizinhos regionais; o dilema entre a conciliação da sua atitude e reconhecimento internacional (a UE, e países como os EUA e alguns estados-membros da UE reconhecem o Brasil como o interlocutor privilegiado da região, do mesmo modo que em fora internacionais a opinião do Brasil passou a ser relevante) e a aceitação, pelos países da sua região, do status internacional, devido à existência de preconceitos históricos que impedem os países da região de reconhecer a relevância internacional do Brasil (como a Argentina e o Paraguai, ou também a Venezuela) (ver, entre outros, Burges, 2009). 


\section{Nota final}

A análise permite-nos constatar uma evidente dinâmica entre o contexto internacional e interno e a formulação da política externa do Brasil. É evidente o reflexo da conjuntura internacional da Guerra Fria na criação de constrangimentos e possibilidades aos atores brasileiros, assim como as condições económicas e políticas internas, especialmente nos momentos de crise, tiveram um impacto nas opções de política externa.

A necessidade de definir a relação com os Estados Unidos, assente durante muito tempo na "aliança não escrita" do princípio do século $\mathrm{XX}$, tem sido uma das marcas da política externa brasileira, especialmente durante e após o período de Guerra Fria. Esta exigência deve-se não apenas aos constrangimentos internacionais, dado o papel hegemónico dos Estados Unidos; mas também à própria posição de vizinhança entre os dois países, partilhando áreas de influência comuns; e com isso o tradicional desejo brasileiro em obter um lugar importante no sistema internacional, o que em alguns momentos choca com os interesses americanos.

A política externa do Brasil tem refletido as tentativas de definição da sua identidade internacional, que deriva das múltiplas identidades que ao longo dos tempos o país foi agregando. A dicotomia entre o contexto interno (pobreza e desigualdade), o crescimento económico e o reconhecimento internacional tem dificultado, inclusivamente, a definição do lugar do Brasil no sistema internacional, o que não deixa de se característico das potências médias. Contudo, cada vez mais se torna evidente, pelo menos no plano externo, a coincidência entre as ambições e as capacidades do Brasil. 


\begin{tabular}{|l|}
\hline Quadro 1. \\
\hline Questões para análise \\
\hline De que forma o sistema política brasileiro determina a formulação da política externa do país? \\
\hline $\begin{array}{l}\text { A política externa brasileira é marcada por um paradoxo de mudanças na continuidade. } \\
\text { Comente esta ideia tendo por base os principais eixos da política externa do Brasil desde a década } \\
\text { de } 1960 .\end{array}$ \\
\hline $\begin{array}{l}\text { O discurso oficial brasileiro enuncia a pertença do Brasil a um espaço regional restrito à } \\
\text { imfluêne do Sul, analise a evolução da política externa brasileira para esta área, tendo em conta as }\end{array}$ \\
\hline $\begin{array}{l}\text { As tentativas de integração regional são uma constante na América do Sul. Identifique os } \\
\text { principais processos e analise o papel do Brasil. }\end{array}$ \\
\hline
\end{tabular}

\begin{tabular}{|l|}
\hline Quadro 2. \\
\hline Fontes na internet \\
\hline Ministério das Relações Exteriores, http://www.itamaraty.gov.br/ \\
\hline O Estado de São Paulo, http://www.estadao.com.br/ \\
\hline Presidência da República Federativa do Brasil, http://www.presidencia.gov.br/ \\
\hline $\begin{array}{l}\text { Revista Brasileira de Política Internacional, http://www.scielo.br/scielo.php?script=sci_ } \\
\text { serial\&pid=0034-7329\&lng=pt }\end{array}$ \\
\hline Revista Contexto Internacional, \\
\hline http://publique.rdc.puc-rio.br/contextointernacional/cgi/cgilua.exe/sys/start.htm?tpl=home \\
\hline
\end{tabular}

\begin{tabular}{|c|}
\hline Quadro 3. \\
\hline Leituras recomendadas \\
\hline $\begin{array}{l}\text { Brainard, L. \& Martinez-Dias, L. (2009) Brazil as an economic superpower? Washington: } \\
\text { Brookings Institution Press. }\end{array}$ \\
\hline $\begin{array}{l}\text { Burges, S. (2009) Brazilian Foreign Policy after the Cold War. Florida: University Press of } \\
\text { Florida. }\end{array}$ \\
\hline $\begin{array}{l}\text { Cervo, A. L. \& Bueno, C. (2008) História da Política Exterior do Brasil. 3. }{ }^{\text {a }} \text { ed. Brasília: } \\
\text { Universidade de Brasília. }\end{array}$ \\
\hline $\begin{array}{l}\text { Spektor, M. (2014) } 18 \text { dias. Quando Lula e FHC se uniram para conquistar o apoio de Bush. } \\
\text { Rio de Janeiro: Objetiva. }\end{array}$ \\
\hline $\begin{array}{l}\text { Vigevani, T. \& Cepaluni, G. (2009) Brazilian Foreign Policy in changing times. The quest for } \\
\text { autonomy from Sarney to Lula. Nova Iorque: Lexington Books. }\end{array}$ \\
\hline
\end{tabular}

\section{Bibliografia}

Amorim, C. (2008) Entrevista ao jornal O Estado de São Paulo, 16/03/2008. [http:// www.mre.gov.br/portugues/politica_externa/discursos/discurso_detalhe3. asp?ID_DISCURSO=3267] (consultado a 12 de março de 2010).

Burges, S. (2009) Brazilian Foreign Policy after the Cold War. Florida: University Press of Florida. 
Cason, J. \& Power, T. J. (2009) «Presidentialization, Pluralization and the rollback of Itamaraty: Explaining change in Brazilian Foreign Policy Making in the Cardoso-Lula Era", International Political Science Review, 116(4), 611-636.

Cervo, A. L. \& Bueno, C. (2008) História da Política Exterior do Brasil, 3. ${ }^{a}$ ed. Brasília: Universidade de Brasília.

Constituição da República Federativa do Brasil (1988). Texto consolidado até a Emenda Constitucional n. ${ }^{\circ} 64$ de 4 de fevereiro de 2010. [http://www.senado. gov.br/legislacao/const/con1988/CON1988_04.02.2010/CON1988.pdf] (consultado a 12 de março de 2010).

Folha Online (2001) «FHC cobra na reunião da ONU ordem internacional mais solidária", 10 novembro. [] (consultado a 12 de março de 2010).

Hirst, M. \& Pinheiro, L. (1995) "A política externa do Brasil em dois tempos», Revista Brasileira de Política Internacional, 38(1), 5-23.

Hirst, M. (2006) "Los desafios de la política sudamericana de Brasil». Revista Nueva Sociedade, 205, 131-140.

Lafer, C. (2002) La identidad internacional de Brasil. Buenos Aires: Fondo de Cultura Economica.

Lafer, C. (2009) "Partidarização da política externa», Jornal O Estado de São Paulo, 20 dezembro.

Lampreia, L. F. (1998) "A política externa do governo FHC: continuidade e renovação", Revista Brasileira de Politica Internacional, 42(2), 5-17.

Lechini, G. (2008) «O Brasil na África ou a África no Brasil? A construção da política africana pelo Itamaraty", Nueva Sociedad. [http://nuso.org/ articulo/o-brasil-na-africa-ou-a-africa-no-brasil-a-construcao-da-politica-africana-pelo-itamaraty/] (consultado a 12 de março de 2010).

Lemos, L. (2010) Brazilian Congress and Foreign Affairs: Abdication or Delegation? Global Economic Governance Programme. [http://www.globaleconomicgovernance. org/wp-content/uploads/GEG-Working-Paper-Lemos.pdf] (consultado a 19 de dezembro de 2010).

Lima, M. R. S. de \& Santos, F. (1998) Brazilian Congress and Foreign Trade Policy. Comunicação apresentada na conferência da Latin American Studies Association. Chicago, Illinois. [http://lasa.international.pitt.edu/LASA98/Soares-Santos.pdf] (consultado a 12 de março de 2010).

Lima, M. R. S. de (2000) "Instituições democráticas e política exterior», Contexto Internacional, 22(2), 265-303.

Lima, M. R. S. de (2007) "Brasil en América Latina. Liderazgo regional en América del Sur». Revista Foreign Affairs en Español, 7(4), 10-12.

Mariano, K. \& Mariano, M. (2008) "A Formulação da política externa brasileira e as novas lideranças políticas regionais», Perspetivas, 33, 99-135.

Mello, C. (1990) [http://www.collor.com/discursos1990_001.asp] (consultado a 12 de março de 2010).

Neves, J. A. de C. (2003) "O Papel do Legislativo nas Negociações do Mercosul e da ALCA", Contexto Internacional, 25(1), 103-138. 
Neto, O. A. (2007) "O poder executivo, centro de gravidade do sistema político brasileiro", in Avelar, L. \& Cintra, A. O. (org), Sistema política brasileiro: uma introdução. Rio de Janeiro: Fundação Konrad Adenauer, 131-141.

Oliveira, M. D. de (org) (2010) Discursos selecionados do Presidente Fernando Henrique Cardoso. Brasília: Fundação Alexandre de Gusmão.

Pecequillo, C. (2008) «Brazil's Foreign Policy in the 21st Century: The Combining Axis of Horizontal and Vertical Multilateral Cooperation", Comunicação apresentada na 49. ${ }^{a}$ Convenção Anual da ISA, São Francisco, EUA, março [http://www. allacademic.com/meta/p254209_index.html] (consultado a 12 de março de 2010).

Saraiva, J. F. S. (1996) O lugar da África. A dimensão atlântica da política externa brasileira. Brasília: Editora Universidade de Brasília.

Saraiva, M. G. (2007) "As estratégias de cooperação Sul-Sul nos marcos da política externa brasileira de 1993 a 2007", Revista Brasileira de Política Internacional, 50(2), 42-59.

Sarney, J. (1986) «Brazil: A President's Story», Foreign Affairs, 65(1).

Silva, L. (2003) Discurso de tomada de posse de Lula da Silva, 1 janeiro. [http:// www.mre.gov.br/portugues/politica_externa/discursos/discurso_detalhe3. asp?ID_DISCURSO=2029] (consultado a 20 de março de 2010).Silva, L. (2003) Discurso de tomada de posse de Lula da Silva, 1 janeiro. [http://www.mre.gov. br/portugues/politica_externa/discursos/discurso_detalhe3.asp?ID_ DISCURSO=2029] (consultado a 20 de março de 2010).

Spektor, M. (2004) «Origens e direcção do Pragmatismo Ecuménico e Responsável (1974-1979)», Revista Brasileira de Política Internacional, 47(2), 191-222.

Spektor, M. (2010) «Ideias de ativismo regional: a transformação das leituras brasileiras da região", Revista Brasileira de Política Internacional, 53(1), 25-44.

Vigevani, T. \& Cepaluni, G. (2009) Brazilian Foreign Policy in changing times. The quest for autonomy from Sarney to Lula. Nova Iorque: Lexington Books.

Vizentini, P. (2003) "A política externa brasileira em transição: do desenvolvimento ao neoliberalismo", in Martins, E. C. de R. (org), Relações Internacionais. Visões do Brasil e da América Latina. Brasília: Instituto Brasileiro de Relações Internacionais, 63-105.

Vizentini, P. (2008) Relações Internacionais do Brasil. De Vargas a Lula. $3 .^{a}$ Edição. São Paulo: Ed. Fundação Perseu Abramo. 